\title{
CORRELATION BETWEEN MORPHOLOGY OF POLYMER COATING'S WITH TEXTURED SURFACE OF METAL AND ITS CORROSION RESISTANCE
}

\author{
${ }^{1}$ Aleksander BAIDZHANOV, ${ }^{1}$ Olga MAKSIMOVA, ${ }^{2}$ Andrei MAKSIMOV \\ ${ }^{1}$ Cherepovets State University, Laboratory of Mathematical and Computer Modeling, Cherepovets, Russia, \\ og62@mail.ru \\ ${ }^{2}$ Cherepovets State University, Department of Physics, Cherepovets, Russia
}

https://doi.org/10.37904/metal.2021.4203

\begin{abstract}
Anti-corrosion protective polymer thin films are used to prevent metal contacting with an aggressive environment. It is known that the density of the polymer film coating can be controlled at the stage of formation its. Based on the results of the simulation of the oxygen ions transport in the polymer film, it was shown that its conductivity increases with an decrease in hte film densitythe. It is also shown that a decrease in the density leads to an increase in the rate of the crack propagation. The images of fractal surfaces simulated on the basis of the Diffusion Limited Aggregation (DLA) algorithm and the reptation model are presented. By comparing the image of the real surface and the simulation results at different values of the coating density, it was shown that there is a correlation between the corrosion resistance and surface texture.
\end{abstract}

Keywords: Textured polymer coating, corrosion resistance, fractal surface, ionic conductivity, salt spray chamber

\section{INTRODUCTION}

Polymer textured coatings of a metal sheets are created by adding granules of polyacrylic, polyamide, etc. to the paintwork material. During the drying process, a radial organization of wrinkles is formed. Moreover, wrinkled domains grow by the diffusion and association in a certain way [1], depending not only on the chemical structure of the material, but also on the drying regime. Wrinkle formation has been studied in many fields such as engineering, materials science, chemistry and physics, but the process of wrinkle formation is not yet fully understood [2]. At the same time, the size and shape of the wrinkles help to describe main properties of the test material [3]. This fact is especially used in biology. For example, examining human skin helps to determine the health status. Non-biological objects are no exception. The purpose of this work is to determine the correlation between the corrosion resistance of a textured polymer coating of a metal sheet and its surface structure.

\section{INFLUENCE OF DENSITY ON ANTI-CORROSION PROPERTIES}

The corrosion is the result of an oxidizing component environment adsorption $\left(\mathrm{O}^{2-}, \mathrm{HO}^{-}, \mathrm{Cl}^{-}\right.$and other) on the metal surface. To prevent a metal contacting with an aggressive environment, anti-corrosion protective polymer thin films are used. The movement of charges in polymers is described most consistently by the models constructed within the hopping mechanism of charge transfer. In the work [4], a model of hopping ionic conductivity through a polymer thin film is presented. It is shown that there is a certain number of molecular layers by which the film is a protective coating against the corrosion. Therefore, the main parameter of the quality of polymer-coated rolled metal is its thickness. However, the results of simulation and the data of production tests [5] showed that there are modes of coating formation, which give an increase in the thickness 
of the polymer coating due to a decrease in the density. For a more detailed study of the ions movement inside the polymer film, a PVDF coating was considered, the macromolecules of which have dipole moment directed perpendicular to the chain backbone and associated with electronegative fluorine and electropositive hydrogen in the composition of side groups (Figure 1). The conformation of the dipoles was calculated according to the method proposed in [6]

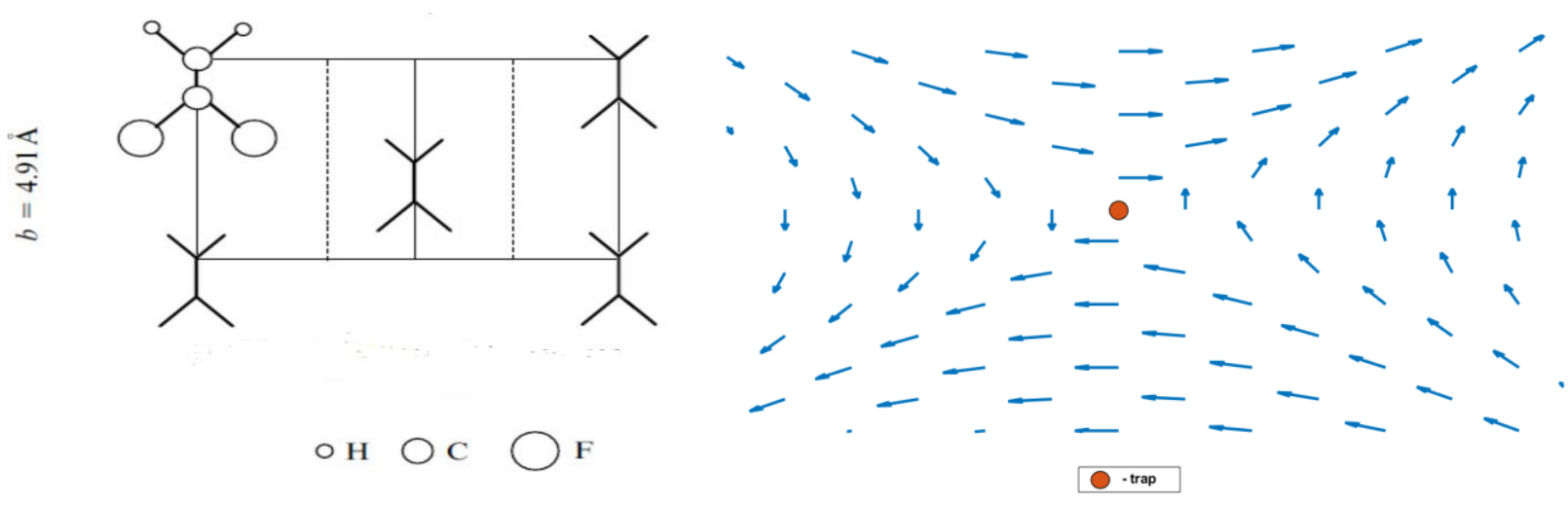

Polymer chains are perpendicular to the plane of the figures

Figure 1 The structure of the PVDF

Figure 2 Location of dipoles near the trap macromolecule [17]

The simulation results showed that the dipoles are located in such a way that points are formed inside the coating, which become natural traps for the ions (Figure 2). The ion located in the bulk of the polymer matrix increases the mobility of the chains. In the presence of oxygen atoms, when the chains are broken, active radicals are formed at their ends (7), which contributes to the formation of nuclei and sustainable crack growth. The crack propagation velocity $V$ in a linear polymer system is determined by the formula[18]:

$$
V \sim \exp \left(\frac{C \cdot b^{2}}{k_{B} \cdot T}\right)
$$

where:

$C$ - the coefficient of proportionality,

$b$ - the intermolecular distance,

$T$ - the temperature.

Therefore, with a decrease in the density of the coating (an increase in the inter-chain distance), the crack propagation speed increases, and, consequently, its anti-corrosion properties decrease. This fact is confirmed by an experiment in a salt spray chamber (Figure 3). The wet coating thickness is the same. During the production of sample 1, the increase in thickness using the appropriate temperature mode was not performed, in contrast to sample 2 , in which the thickness was artificially increased by $0.3 \mu \mathrm{m}$. The experimental results showed that even a slight decrease in the density of the coating leads to a violation of the corrosion resistance. However, it is not possible to measure the density of the coating by conventional laboratory methods. Therefore, we need to use indirect methods that will not be time-consuming, like a salt spray chamber. 


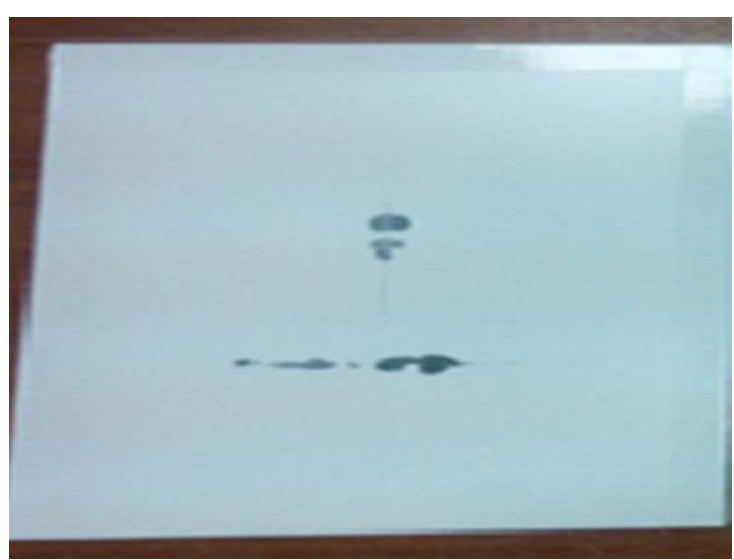

Sample 1

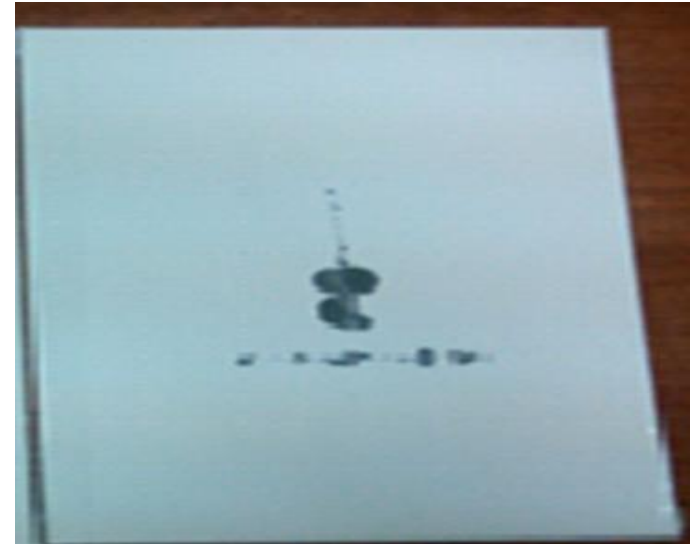

Sample 2

Figure 3 Images of samples of rolled metal with a polymer coating 500 hours after the experiment in the salt spray chamber

\section{INFLUENCE OF DENSITY ON SURFACE MORPHOLOGY}

The polymer surface is usually represented by fractal functions [8-13]. The most adequate method for modeling the surface morphology of a textured polymer coating is the diffusion limited aggregation method [14]. In this model, the initial position of the particle on the circle surrounding the granule is randomly selected. Then it starts to walk around the surface. Its coordinetes $x_{k, j}$ and $y_{k, j}$ are changed by the equation (2)

$x_{k+1, j}=x_{k, j}+\Delta r \cdot \cos (\varphi)$

$y_{k+1, j}=y_{k, j}+\Delta r \cdot \sin (\varphi)$

where:

$j$ - the particle number

$k$ - the step number

$\Delta r$ - the step length

The angle $\varphi$ in the formulas (2) is measured from the direction of motion of the particle in the previous step. But the random walk of particles in this model is based on the uniform distribution of the angle [14].

However, such a model of motion is not acceptable for polymer systems, since it does not take into account the density of the medium, the rigidity of the chain, and its limitations on the mobility. Therefore, in this work, we used the reptation model [15], in which the chain moves inside a tube of diameter $d$. According to this model, the angle $\varphi$ distribution is Gaussian.

$$
f(\varphi)=\frac{1}{\sigma \cdot \sqrt{2 \cdot \pi}} \cdot \exp \left(-\frac{\varphi^{2}}{2 \cdot \sigma^{2}}\right)
$$

where:

$\sigma$ - the standard deviation $\sigma$ can be estimated from the expression $\sigma=b / l$

$I$ - the length of the Kunn segment 
$d$ - the tube diameter equal to the interchain distance

For example, for PVDF: $b=4.9 \AA, I=30 \AA, \sigma=0,16$. Naturally, with an artificial decrease in density, the interchain distance increases according the formula $b=\sqrt{\frac{m_{0}}{\rho \cdot a}}$, where $\rho$ is the density of the polymer coating, $m_{0}$ and $a$ are the mass and length of the polymer chain segment.

Figure 4 shows the resulting fractal surfaces for different values of the parameter $\sigma$.

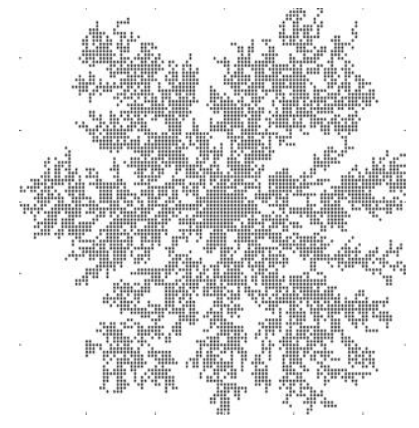

a)

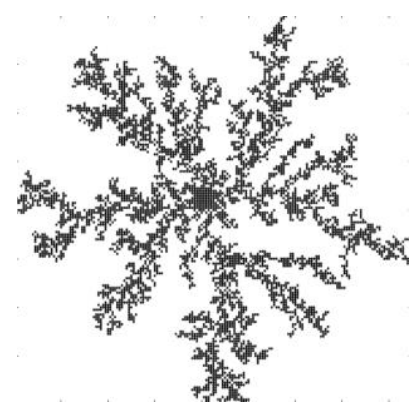

b)

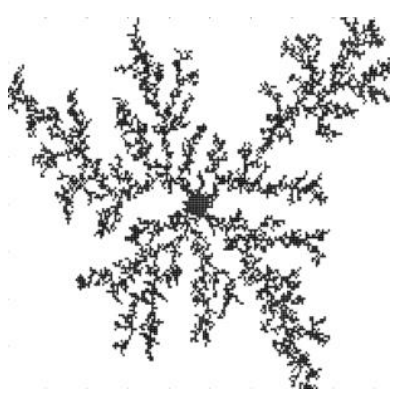

c)

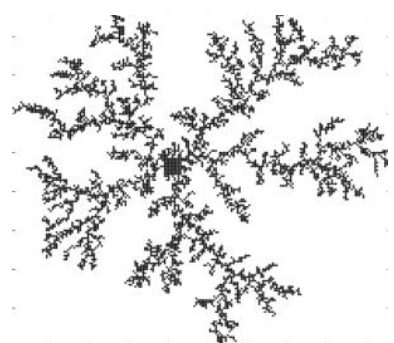

d)

Figure 4 Results of the surface simulation for different values of the parameter $\sigma$.

a) $\sigma=0.1 \mathrm{~b}) \sigma=0.4 \mathrm{c}$ ) $\sigma=0.7 \mathrm{~d}$ ) uniform distribution

Figures $\mathbf{5 a}$ and $\mathbf{5 b}$ show images of the surface of a textured polymer coating obtained with an optical microscope. In Figure $\mathbf{5 b}$, the density is artificially reduced by $15 \%$, in contrast to the sample shown in (Figure 5a). As you can see, "star clusters" become anisotropic with decreasing density. Therefore, to compare the simulation and experimental data, we introduced the anisotropy parameter of the constructed fractal model using the formula.

$$
\alpha=\frac{4 \cdot S}{\pi \cdot L^{2}}
$$

where:
$S$ - the area of the polygon paving the fractal
$L$ - the length of the median line (Figure 4).

Figure 6 shows the dependence of the anisotropy parameter a on the standard deviation. As you can see from the figure, with increasing the anisotropy parameter decreases. This is most important for polymers with a low parameter value, such as PVDF. For this polymer, even a slight decrease in density will lead to a change in surface morphology.

To construct a three-dimensional image, we have the model [16] with the following modifications: after the particle reached the granule or growing cluster, its coordinates were replaced in the center of the hemisphere, which was added to the data array by summing the values on the matching cells. The simulation results are shown in (Figures $\mathbf{5 c}$ and $\mathbf{5 d}$ ). 

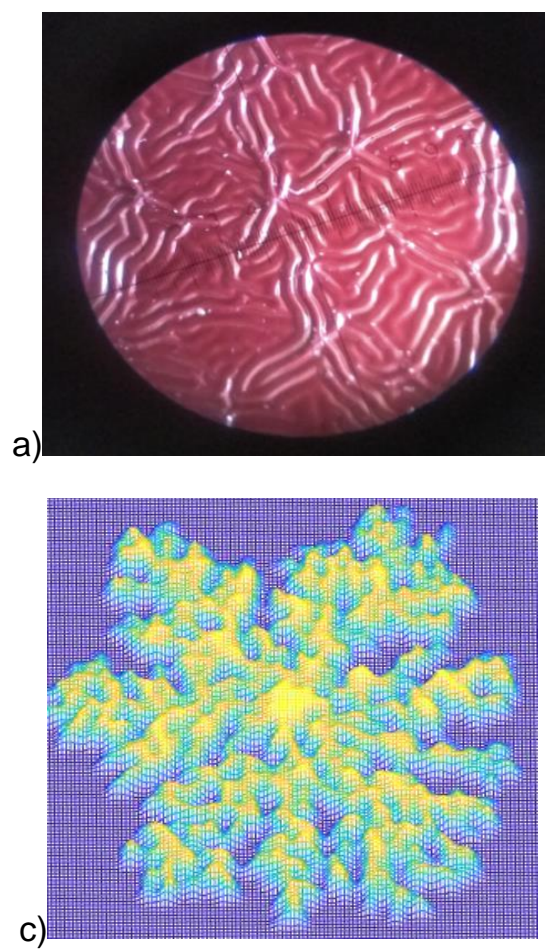

b)

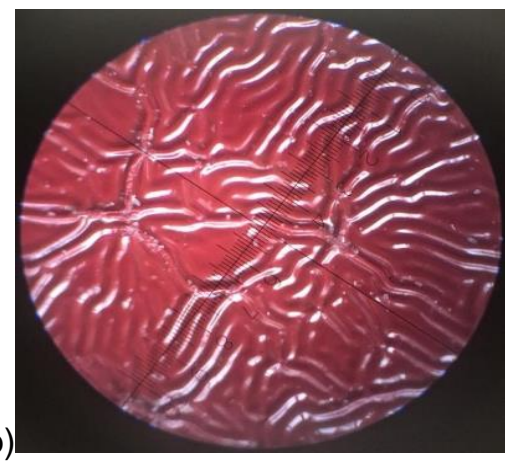

d)

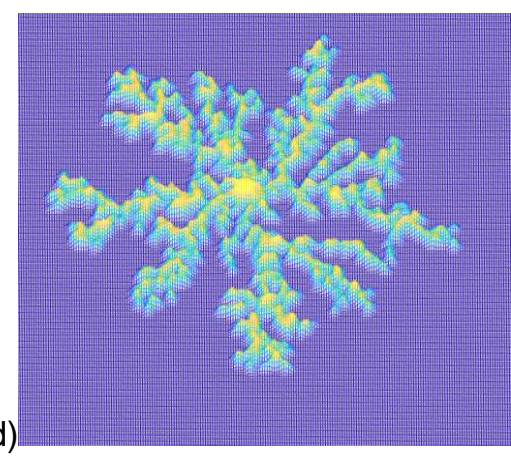

Figure 5 Images of the surface of a textured polymer coating of a metal sheet obtained with the optical microscope ( $\mathbf{a}$ and $\mathbf{b}$ ) and their fractal three-dimensional models ( $\mathbf{c}$ and $\mathbf{d}$ ). Coating density in (Figures a and c) are larger than in (Figures $\mathbf{b}$ and $\mathbf{d}$ ).

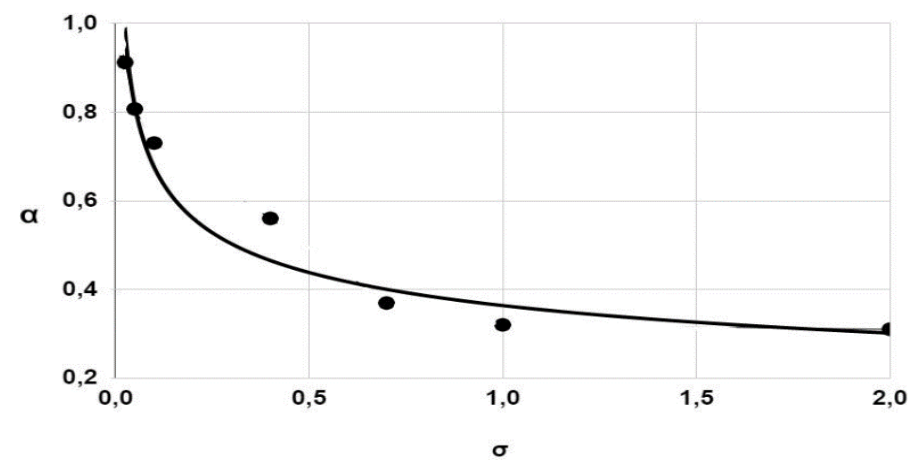

Figure 6 The anisotropy parameter $\alpha$ vs. the parameter $\sigma$
Figure 6 shows the dependence of the anisotropy parameter $\alpha$ on the standard deviation. As you can see from the figure, with increasing the anisotropy parameter decreases. This is most important for polymers with a low parameter value, such as PVDF. For this polymer, even a slight decrease in density will lead to a change in surface morphology.

\section{CONCLUSION}

With a decrease in the density of the polymer coating of the metal during its drying, the anticorrosive properties decrease. But in this case, there is also a change in the surface morphology, which can be observed with the optical microscope. A change in the anisotropy of "star clusters" on the surface of textured polymer coatings results in a violation of product quality.

\section{ACKNOWLEDGEMENTS}

This study was supported by the Russian Foundation for Basic Research, project No. 19-42-350001. 


\section{REFERENCES}

[1] HUGUES, V., SYLVAIN, G., FABIAN, B., CYPRIEN, G., KEVIN, K. Parkerc and Pascal Damman. Hierarchical wrinkling patterns. Soft Matter. 2010, vol. 6, pp. 5751-5756.

[2] SHIMOKAWA, M., YOSHIDA, H., KOMATSU, T., OMACHI, R. and KUDO, K. Emergence of Wrinkles during the Curing of Coatings. Gels. 2018, vol. 4, p. 41.

[3] JAN, G., JAN, G. Soft matter with hard skin: From skin wrinkles to templating and material characterization. Soft Matter. 2006, vol. 2, pp. 310-323.

[4] MAKSIMOVA, O., MAKSIMOV, A., DIORDIICHUK, D. Investigation of corrosion resistance of steel with polymer coatings. In: METAL 2015: 24th International Conference on Metallurgy and Materials. Ostrava: TANGER, 2015, pp. 941-946.

[5] MAKSIMOVA, O., MAKSIMOV, A., MOISEEVA, A. Influence of interface on the formation process of polymer coatings on metal. Journal of Advanced Dielectrics. 2016, vol. 6, no. 01, pp. 1-5.

[6] MAKSIMOVA, O., PISKUNOV, O., GERASIMOV, R., BARUZDINA, O., MAKSIMOV, A. Computer simulation of shearing deformation in polymer systems with polar groups. Journal of Advanced Dielectrics. 2020, vol. 10, no. 03, pp. 1-6.

[7] KAUSCH, H. Polymer Fracture, Polymers - Properties and Applications (t 2). Verlag Berlin Heidelberg: Springer, 2012 (reprint of 1987).

[8] SEMCHUK, O.Y., GRECHKO, L.G., VODOPIANOV, D.L., KUNITSKA, L.Y. Features of light scattering by surface fractal structures. Taskquarterly. 2009, vol. 13, no. 3, pp.199-206.

[9] LIN, N., LEE, H.P., LIM, S.P., LEE, K.S. Wave Scattering from Fractal Surfaces. J. Mod. Opt. 1995, vol. 42, no. 1 , p. 225.

[10] WANG, M., LI, J., REN, L. Characteristics of EM scattering on dielectric fractal surface. Chinese Science Bulletin. 1997, vol. 42, no. 6, pp. 523-526.

[11] TORKHOV, N. A., BOZHKOV, V.G. Fractal character of the distribution of surface potential irregularities in epitaxial n- gaas. Semiconductors. 2009, vol. 43, no. 5, p. 551.

[12] KUZMIN, O.V., MALAKICHEV, A.O. Geometric fractals modeling through infinite graphs. Modern technologies. System analysis. Modeling. 2012, vol. 35, no. 3., p. 79.

[13] GEHANI, A., AGNIHOTRI, P., PUJARA, D. Analysis and synthesis of Multiband Sierpinski carpet fractal antenna using hybrid neuro-fuzzy model. Progress in electromagnetics research letters. 2017, vol. 68, pp. 59-65.

[14] RUZHITSKAYA, D.D., RYZHIKOV, S.B., RYZHIKOVA, Y.V. The Optical Properties of Fractal Nanodendrites in the Processes of Their Self-Organization. Moscow Univ. Phys. [online]. 2018, vol. 73, pp. 306-309. Available from: https://doi.org/10.3103/S0027134918030165.

[15] DOI, M., EDWARDS, S. F. The Theory of Polymer Dynamics. Oxford: Clarendon Press, 1986.

[16] MAKSIMOVA, O., BAIDGANOV, A., PETROVA, T., MAKSIMOV, A., EGOROV, V. Simulation of the Surface of Metal Sheet with Textured Polymer Coating by Method of Diffusion-Limited Aggregation. In: Proceedings 28th International Conference on Metallurgy and Materials. [online]. Ostrava: TANGER, 2019, pp. 903-908. Available from: https://doi.org/10.37904/metal.2019.737

[17] KOCHERVINSKY, V. V. The properties and applications of fluorinecontaining polymer films with piezo- and pyroactivity. Russ. Chem. Rev. 1994, vol. 63, p. 367.

[18] BARTENEV, G. M., FRENKEL, S. Y. Physics Polymers. Leningrad: Khimiya, 1990. 